\title{
GAMBARAN IMPLEMENTASI SANITASI LINGKUNGAN PADA MASYARAKAT (STUDI PADA MASYARAKAT DI DESA BANRA'AS PULAU GILI IYANG) TAHUN 2020
}

\author{
Laylatul Hasanah ${ }^{1)}$, Enza Resdiana ${ }^{1)}$ \\ ${ }^{1)}$ FIK Universitas Wiraraja
}

\begin{abstract}
Abstrak
Sanitasi lingkungan merupakan suatu hal yang sering kita dengar yang meliputi mencakup penyediaan air bersih, pembuangan kotoran, pembuangan sampah. Penelitian ini memiliki tujuan untuk mengetahui Implementasi sanitasi lingkungan pada masyarakat di Desa Banra'as Gili Iyang di Kabupaten Sumenep tahun 2020. Peneilitian ini adalah penelitian deskriptif kualitatif dengan menggunakan pendekatan wawancara dan Observasi lapangan. Penelitian ini dilakukan di Desa Banra'as Pulau Gili Iyang pada bulan september tahun 2020. Obyek pada penelitian ini adalah Kepala Desa, perangkat Desa dan Masyarakat sebanyak 10 orang sebagai informan. Instrumen penelitian menggunakan lembar wawancara, dan lembar observasi untuk menggambarkan kondisi masyarakat di pulau Gili Iyang.

Hasil penelitian menunjukkan bahwa masyarakat di Desa Banra'as belum menerapkan sanitasi dengan baik ditunjukkan oleh hasil wawancara bahwa 50\% masyarakat masih menggunakan WC terbuka, 50\% masyarakat membuang limbah ke ruang terbuka, $700 \mathrm{KK}$ masih tidak memiliki sumber air bersih sendiri, dan 100\% masyarakat di Banra'as membakar limbah rumah tangga (sampah) di lahan terbuka.
\end{abstract}

Kata Kunci: Implementasi Sanitasi Lingkungan, Pulau Gili Iyang

\begin{abstract}
Environmental sanitation is one of the problem that occur in the society.That problem often we hear and see in the society which includes the provision of clean water, sewage disposal, and garbage disposal. The aims of this study to determine the implementation of environmental sanitation in society in Gili Iyang in Sumenep Regency at 2020. This research use qualitative descriptive study using an interview and observation. This research was conducted in the village of Banra'as on Gili Iyang Island in September 2020. Object of this study is the principal of the village, stuff of the village, society and 10 informants. The research instrument used interview sheets and observation sheets to describe the conditions of the people on the island of Gili Iyang.

The results showed that the community in Banra'as Village had not implemented sanitation properly, indicated by the results of the interview that 50\% of the community still used open toilets, 50\% of the community disposed of waste into open spaces, 700 families still did not have their own clean water sources, and 100\% people in Banra'as burn household waste (garbage) in open land.Keywords: Banana Peel, Bioactivator, compost.
\end{abstract}

Keywords: Implementation of Enviromental sanitation, Gili Iyang Island

\section{Pendahuluan}

Masalah sanitasi di Indonesia merupakan hal yang lumrah terjadi, hal tersebut disebabkan beberapa faktor antaranya yakni kurangnya perhatian oleh pemerintah atau dinas terkait pada sektor sanitasi, minimnya ketersedian air bersih dan sanitasi, minimnya ketersediaan ruang, berperilaku bersih masih minim, serta minimnya sanitasi ditempattempat umum seperti sekolah, rumah sakit, puskesmas, masjid, tempat rekreasi, restoran dan lain- lain. Kesehatan pada masyarakat juga dapat dipengaruhi oleh persyaratan

yang memenuhi pada bagian tertentu misalnya terpenuhinya syarat-syarat kesehatan lingkungan pada tempat-tempat umum.

Sanitasi berasal dari bahasa Inggris yakni sanitation yang berarti perilaku yang disengaja dilakukan dalam rangka mencegah manusia memiliki kontak langsung dengan kotoran serta bahan buangan lainnya yang dapat membahayakan manusia dan 
lingkungan dengan harapan usaha ini dapat menjaga dan meningkatkan derajat kesehatan masyarakat.

Pulau Gili Iyang Madura yang memiliki oksigen terbaik di dunia ini hanya salah satu dari Pulau yang ada di wilayah Sumenep, Jawa Timur. Sumenep memiliki 126 pulau kecil, salah satu diantara pulau yang berpenghuni adalah Pulau Gili Iyang yang secara geografis berada di kecamatan Dungkek, kabupaten Sumenep, Jawa Timur. Pulau Giliyang terbagi menjadi dua desa, yaitu Desa Bancamara dan Desa Banra'as.

Berdasarkan hasil wawancara awal dengan kepala Desa Banra'as bahwa masyarakat di Desa Banra'as Gili iyang banyak yang tidak menerapkan sanitasi dengan baik, sehingga perlu dilakukan penelitian mengenai implementasi penerapan sanitasi lingkungan di Desa Banra'as Gili Iyang.

Sanitasi merupakan usaha yang dilakukan oleh masyarakat untuk mencipatakan suatu lingkungan atau suatu keadaan yang leibih baik di bidang kesehatan terutama dalam kesehatan masyarakat. Sanitasi juga adalah salah satu usaha preventif yang yang titik beratnya adalah kepada usaha kesehatan lingkungan dan juga pengawasan, pengendalian serta beberapa faktor lingkungan dan fisik manusia yang dapat menimbulkan dampak buruk terhadap kehidupan manusia baik secara mental maupun fisik. (WHO, 2017).

Sanitasi juga memiliki tujuan agar kebersihan lingkungan terjamin sehingga dapat mewujudkan kondisi yang sesuai dengan syarat kesehatan serta dapat mengembalikan, memperbaiki dan mempertahankan kesehatan manusia, manfaat sanitasi juga dapat meningkatkan kesehatan manusia dengan adanya pengendalian lingkungan. Berdasarkan rinciannya manfaat sanitasi merupakan kondisi terciptanya lingkungan yang bersih, sehat, dan nyaman bagi manusia serta dapat mencegah dan meminimalkan adanya penularan penyakit, adanya kecelakaan, polusi akibat emisi, dan berkurangnya persentase penyakit dan orang sakit di suatu daerah.

Upaya untuk mewujudkan kualitas lingkungan yang sehat, keadaan lingkungan yang bebas dari resiko, keselamatan pada kehidupan manusia, kesehatan lingkungan pada permukiman, lingkungan kerja, kawasan industri dan sejenisnya juga disebut dengan sanitasi. Upaya selanjutnya yang dilakukan dalam menjaga dan memelihara kesehatan lingkungan adalah objek sanitasi yang meliputi seluruh tempat kita tinggal/bekerja, dan yang disebut dengan sanitasi lingkungan terdiri dari air bersih, kepemilikan jamban dan limbah rumah tangga.

Air merupakan kebutuhan pokok yang harus digunakan dalam kehidupan sehari-hari untuk minum, memasak, mandi, berkumur, membersihkan lantai, mencuci alat-alat dapur, mencuci pakaian, dan sebagainya, agar kita tidak terkena penyakit atau terhindar dari sakit.
Persyaratan yang harus dipenuhi dalam penggunaannya adalah air bersih yang baik secara fisik yang menjadi standart air bersih yakni dapat dibedakan melalui indera kita, antara lain (dapat dilihat, dirasa, dicium, dan diraba) Air tidak berwarna harus bening/jernih, Air tidak keruh, harus bebas dari pasir, debu, lumpur, sampah, busa, dan kotoran lainnya, Air tidak berasa, tidak berasa asin, tidak berasa asam, tidak payau,dan tidak pahit, harus bebas dari bahan kimia yang memiliki kandungan racun dan tidak memiliki bau amis, anyir, busuk atau bau yang lainnya. Air memiliki manfaat agar terhindar dari gangguan penyakit seperti diare, kolera, disentri, thypus, kecacingan, penyakit mata, penyakit kulit atau keracunan dan Setiap anggota keluarga terpelihara kebersihan dirinya.

Jamban sehat efektif untuk memutus mata rantai penularan penyakit. Jamban sehat harus dibangun, dimiliki, dan digunakan oleh keluarga dengan penempatan (di dalam rumah atau di luar rumah) yang mudah dijangkau oleh penghuni rumah.

\section{Bahan dan Metode}

Metode penelitian ini menggunakan deskriptif kualitatif yakni metode yang menggambarkan keadaan atau kondisi yang real tanpa direkayasa, tanpa adanya perlakuan atau manipulasi terhadap variabel yang diteliti. Jenis penelitian deskriptif kualitatif merupakan jenis penelitian dengan proses memperoleh data bersifat apa adanya. (Nazir, 2011)

\section{Hasil dan Pembahasan}

Pulau Gili Iyang terdiri dari dua Desa yakni Desa Bancamara dan Desa Ban Ra'as, Kedua Desa tersebut memiliki ciri-ciri wilayah dan masyarakat yang memiliki perilaku serupa kehidupan di masyarakat beraneka ragam, salah satu contoh adalah perilaku masyarakat dalam mengaplikasikan sanitasi kesehatan. Penerapan sanitasi dasar di Desa Ban Ra'as 1705 KK dengan jumlah masyarakat 3200, penerapan sanitasi di Desa Banra'as masih kurang baik hal ini dibuktikan berdasarkan hasil wawancara dengan kepala Desa, Aparat Desa serta masyarakat dan observasi dilakukan untuk melihat kondisi lingkungan secara langsung. Penelitian yang dilakukan meliputi beberapa item diantaranya, penggunaan air bersih, air minum, pembuangan dan pengelolaan sampah serta limbah rumah tangga di Desa Banra'as Pulau Gili iyang.

a. Penggunaan Air Bersih

Air bersih yang digunakan oleh masyarakat di Desa Banra'as Pulau gili Iyang merupakan air bersih yang berasal dari sumur gali dan IPAM yang dimiliki oleh swasta yakni air bersih yang berasal dari sumur masyarakat yang kemudian dijual dan didistribusikan pada masyarakat luas. 
“Kalau air bersih di Desa Banra'as berasal dari sumur gali yang dimiliki oleh masyarakat dan ada IPAM yang setiap IPAMnya punya 700 pelanggan , tapi kadang airnya payau, yaa sumbernya sama juga dari sumur bor tapi dikelola oleh perorangan menggunakan saluran. Dan Alhamdulillaaah semuanya terpenuhi, meskipun kadang airnya payau. "(M, kepala Desa 41).

"Kalau air bersih di Desa Banra'as berasal dari sumur gali yang dimiliki oleh masyarakat dan ada IPAM yang setiap IPAMnya punya sekitar 700 pelanggan, tapi kadang airnya payau, yaa sumbernya sama juga dari sumur bor tapi dikelola oleh perorangan menggunakan saluran. Dan Alhamdulillaaah semuanya terpenuhi, meskipun kadang airnya payau. "(M, kepala Desa 41). "Mun aeng e ka'enjeh bu ngangguy somor bu, ngangguy timba padenah nika.. gi bede se melle". (L, Masyarakat, 34)."kalau air disini berasal dari air sumur bu, ngambilnya menggunakan ember, tapi ada juga yang beli” (L, Masyarakat, 34).

Persyaratan lainnya yang menjadi penting agar air tersebut dapat digunakan adalah memperhatikan jarak sumur dengan $\mathrm{WC}$ atau tempat pembuangan akhir limbah atau sampah yang paling sedikitnya minimal 10 meter. Sumber mata air, sumur pompa, sumur gali, kran umum dan mata air merupakan beberapa aspek lingkungan yang harus dilindungi dari adanya cemaran. Pencegahan serta perlindungan terhadap cemaran dapat dilakukan dengan menjaga bangunan agar tidak rusak, tidak retak, bibir sumur harus diplester serta memberi penutup pada sumur. Kebersihan selanjutnya yang perlu dijaga adalah tidak adanya genangan air, tidak ada bercak kotoran, tidak ada lumut pada lantai/dinding sumur serta Ember/gayung pengambil air harus tetap bersih dan tidak diletakkan di lantai (ember/gayung digantung di tiang sumur). (Kemenkes, 2019)

Namun berdasarkan hasil observasi hal tersebut tidak sepenuhnya terpenuhi di sumur masyarakat di Gili Iyang, sumur yang dimiliki masyarakat tidak memiliki tutup serta dinding sumur yang dimiliki oleh masyarakat tidak dilapisi oleh semen atau diplester namun tanah langsung.

\section{b. Kepemilikan Jamban}

"50\% masyarakat menggunakan WC di dalam rumah masing-masing dan WC cemplung, 50\% masyarakat belum memiliki Wc, Nah ini juga PR buat saya". (M, kepala Desa 41).

“ 50\% masyarakat menggunakan WC di dalam rumah masing-masing dan WC cemplung, 50\% masyarakat belum memiliki Wc, Nah ini juga PR buat saya". (M, kepala Desa 41).

"Masyarakat eka'enjeh ngangguy WC cemplung bu, gi bede jugen se andik WC keng tak pas kakabbi” (F, Aparat Desa 42)
"Masyarakat di sini menggunakan WC cemplung bu, ada juga beberapa yang memiliki WC di rumahnya, tapi tidak semua" ( $F$, Aparat Desa 42)

"gi mon kaule ngangguy kakus nikah bu, nyambi aeng mun a ngingi'ah" (S, Masyarakat 40)

"Kalau saya menggunakan WC ini bu, (sambil menunjuk WC cemplung), kalau mau BAB saya membawa air kesini.”(S, Masyarakat 40)

Berdasarkan Environment Health Risk Assessment (EHRA) yang dilakukan ISSDP di enam kota, presentase yang terbesar adalah rumah tangga yang memiliki jamban namun sekitar 64\% masih membuang limbah cairnya ke lahan terbuka. Survei tersebut juga menunjukkan bahwa $60 \%$ masyarakat di pedesaan tidak memiliki akses terhadap jamban yang memenuhi syarat, $40 \%$ masyarakat juga membuang limbah cair dari limbah buangan bukan ke septic tank tapi langsung dibuang ke lingkungan seperti sungai, lahan dan ruang terbuka lainnya. Hal tersebut berkaitan dengan kurangnya kualitas pengolahan limbah cair yang tidak memadai dipedesaan atau di kota. Di seluruh Indonesia Instalasi pengolahan Air limbah (IPAL) terdapat 12 Kabupaten/Kota belum menyediakan IPAL yang memenuhi syarat. Salah satu syarat IPAL adalah tertutup sehingga dapat mengurangi resiko yang dapat memicu penyebaran penyakit berbasis lingkungan akibat tercemarnya air tanah.

Terwujudnya perilaku hidup bersih dan sehat sebagaimana tercantumkan pada peraturan kementerian kesehatan dalam pasal 3 ayat 2 yakni salah satunya adalah melakukan BAB di sembarang tempat. Budaya perilaku buang air besar yang sehat dapat memutus adanya aliran kontaminasi antara manusia dan sumber pencemar tersebut, sarana yang digunakan pada saat BAB juga merupakan sumber kontaminan yang cukup mempengaruhi apabila syarat-sayarat yang telah dianjurkan tidak dipenuhi.

Bangunan jamban yang memenuhi syarat terdiri dari bangunan atas jamban (dinding dan/atau atap) yang berfungsi untuk melindungi dari cuaca dan gangguan lainnya. Bangunan jamban yang memenuhi syarat memiliki 2 bagian yakni bagian tengah jamban, tempat pembuangan kotoran (tinja dan kencing) yang berbentuk leher angsa. Kontruksi sederhananya (semi saniter) lubang dapat dibuat tanpa konstruksi leher angsa, diberi tutup, lantai yang kedap air, tidak licin dan mempunyai saluran untuk pembuangan limbah bekas ke SPAL. (Kemenkes,2014)

Berdasarkan hasil wawancara dan observasi lapangan jamban yang dimiliki oleh masyarakat di Desa Banra'as Pulau Gili Iyang 50\% tidak memenuhi syarat, karena masyarakat di Desa Banra'as menggunakan WC cemplung atau bahkan ruang terbuka untuk melakukan BAB. 
c. Limbah cair dan padaat rumah tangga

"limbah kotoran (pacarren) langsung ke lahan

dari kamar mandi, ada sekitar $70 \%$ yang melakukannya, alasan masyarakat biar pohon yang ada dilahan rindang .. hahaha. "(M, kepala Desa 41).

"Limbah kotoran atau limbah cair dari kamar mandi langsung dibuang ke lahan oleh masyarakat, ada sekitar $70 \%$ yang melakukannya, alasan masyarakat membuang langsung ke lahan biar pohon yang ada di lahan rindang.. hahaha" "'(M, kepala Desa 41).

"kalau sampah tidak ada pengelolaan lebih lanjut bu, 100\% masyarakat membakar sampah atau limbah rumah mereka, jadi gak ada pengelolaan sampah lanjutan bu." "(M, kepala Desa 41).

"“kalau sampah tidak ada pengelolaan lebih lanjut bu, $100 \%$ masyarakat membakar sampah atau limbah rumah mereka, jadi gak ada pengelolaan sampah lanjutan bu." "(M, kepala Desa 41).

"Mun rombuh e ka'enjeh e obber bu e talon, tak paberemma-epaberemma pole ten". (Masyarakat, 45) "kalau sampah disini dibakar di lahan, gak digimana-gimanain lagi”. (Masyarakat, 45).

Kebiasaan dan budaya memilah dan memilih serta pengolahan sampah rumah tangga dalam Peraturan Menteri Kesehatan Republik Indonesia
Nomor 3 Tahun 2014 Tentang Sanitasi Total Berbasis Masyarakat Pasal 3 ayat 2 adalah

Budaya memilah jenis sampah berdasarkan klasifikasi persyaratan jenis sampah tersebut, budaya membuang sampah di luar rumah secara rutin untuk mengurangi sampah (reduce), menggunakan kembali sampah tersebut dengan fungsi yang berbeda (reuse), serta dilakukan pengolahan kembali terhadap sampah itu lagi (recyle).

Perilaku Pengamanan Limbah Cair Rumah Tangga sebagaimana dimaksud dalam Pasal 3 ayat 2 adalah dilakukannya pemisahan antara limbah cair dan rumah tangga melalui sumur resapan yang dibuat khusus untuk menampung air limbah cair, memelihara saluran pembuangan dan penampungan limbah cair rumah tangga.(Kemenkes, 2014).

\section{Kesimpulan}

a. Penggunaan air bersih di Desa Banra'as masih belum memenuhi syarat karena air bersih yang dimiliki masyarakat terasa payau.

b. Masyarakat di Desa Banra'as $50 \%$ belum memiliki jamban yang memenuhi syarat.

c. Limbah cair dan padat yang diperoleh dari hasil kegiatan rumah tangga 100\% langsung di buang ke lahan atau lingkungan terbuka.

\section{Daftar Pustaka}

Resty Aprilia Utami, 2018 Terhadap Kesehatan Masyarakat Di Wilayah Pesisir Kecamatan Kota Agung Bandar Lampung

Eri Trinurini Adhi, 2017 Pelayanan Sanitasi Buruk: Akar Dari Kemiskinan

Peraturan Menteri Kesehatan Republik Indonesia Nomor 3 Tahun 2014 Tentang Sanitasi Total Berbasis Masyarakat

Agsa, Devi dan Evi, 2013 Hubungan Personal Hygiene dan Sanitasi Lingkungan dengan Keluhan Penyakit Kulit di Kelurahan Denai Kecamatan Medan Denai Kota Medan Tahun 2012

Alifia, Mursid \& Nikie, 2016 Hubungan Kualitas Sanitasi Lingkungan Dan Bakteriologis Air Bersih Terhadap Kejadian Diare Pada Balita Di Wilayah

Selin dan Priyatno, 2018 Analisis Implementasi Program Penyediaan Air Minum dan Sanitasi Berbasis Masyarakat (PAMSIMAS) II Kabupaten Semarang (Studi Kasus Desa Timpik Kecamatan Susukan)
Kiki Rizky Amalia, 2019 Evaluasi Pengelolaan Program Penyediaan Air Minum dan Sanitasi Berbasis Masyarakat di Jorong Gurun Kecamatan Harau Kabupaten Lima Puluh Kota

Kerja Puskesmas Adiwerna Kabupaten Tegal, Jurnal Kesehatan Masyarakat (E-Journal)

Kasnodihardjo, Elsa, 2013 Deskripsi Sanitasi Lingkungan, Perilaku Ibu, dan

Kesehatan Anak, Pusat Teknologi Intervensi Kesehatan Masyarakat Badan Penelitian dan Pengembangan Kesehatan Kementerian Kesehatan Republik Indonesia 